\title{
Molecular cloning and expression pattern of oriental river prawn (Macrobrachium nipponense) nitric oxide synthase
}

\author{
N.M.A. Rahman ${ }^{1,3}$, H.T. Fu ${ }^{1,2}$, S.M. Sun ${ }^{2}$, H. Qiao ${ }^{2}$, S. Jin ${ }^{1,2}$, H.K. Bai ${ }^{1}$, \\ W.Y. Zhang ${ }^{2}$, G.X. Liang ${ }^{1}$, Y.S. Gong ${ }^{1}$, Y.W. Xiong ${ }^{2}$ and Y. Wu ${ }^{1}$ \\ ${ }^{1}$ Wuxi Fisheries College, Nanjing Agricultural University, Wuxi, China \\ ${ }^{2}$ Key Laboratory of Freshwater Fisheries and Germplasm Resources Utilization, \\ Ministry of Agriculture, Freshwater Fisheries Research Center, \\ Chinese Academy of Fishery Sciences, Wuxi, China \\ ${ }^{3}$ Fisheries Research Center, \\ Animal Research Corporation of the Ministry of Animal Resources, \\ Khartoum, Sudan \\ Corresponding author: H.T. Fu \\ E-mail: fuht@ffrc.cn
}

Genet. Mol. Res. 15 (3): gmr.15038541

Received February 11, 2016

Accepted May 5, 2016

Published August 29, 2016

DOI http://dx.doi.org/10.4238/gmr.15038541

Copyright $(C 2016$ The Authors. This is an open-access article distributed under the terms of the Creative Commons Attribution ShareAlike (CC BY-SA) 4.0 License.

\begin{abstract}
Nitric oxide synthase (NOS) produces nitric oxide (NO) by catalyzing the conversion of L-arginine to L-citrulline, with the concomitant oxidation of nicotinamide adenine dinucleotide phosphate. Recently, various studies have verified the importance of NOS invertebrates and invertebrates. However, the NOS gene family in the oriental river prawn Macrobrachium nipponense is poorly understood. In this study, we cloned the full-length NOS complementary DNA from $M$. nipponense (MnNOS) and characterized its expression pattern in different tissues and at different developmental stages.
\end{abstract}


Real-time quantitative polymerase chain reaction (RT-qPCR) showed the MnNOS gene to be expressed in all investigated tissues, with the highest levels observed in the androgenic gland $(\mathrm{P}<0.05)$. Our results revealed that the $M n N O S$ gene may play a key role in M. nipponense male sexual differentiation. Moreover, RT-qPCR revealed that MnNOS mRNA expression was significantly increased in post-larvae 10 days after metamorphosis $(\mathrm{P}<0.05)$. The expression of this gene in various tissues indicates that it may perform versatile biological functions in $M$. nipponense.

Key words: Macrobrachium nipponense; Nitric oxide synthase; Cloning; Expression pattern; RT-qPCR; Post-larvae

\section{INTRODUCTION}

Nitric oxide synthase (NOS) catalyzes nitric oxide (NO) biosynthesis via the conversion of L-arginine to L-citrulline, with the concomitant oxidation of nicotinamide adenine dinucleotide phosphate (NADPH) (Moncada et al., 1991). Kubes et al. (1991) described the multiple roles of NOS, including in the regulation of vasomotor tone, cell adhesion to the endothelium, inhibition of platelet aggregation (Radomski et al., 1991), and vascular smooth muscle cell proliferation. In response to pathological stimuli, NOS stimulates macrophages, Kupffer cells, neutrophils, fibroblasts, vascular smooth muscle, and endothelial cells (Eddy, 2005). Argininederived NO synthesis has been observed in mammals, fish, birds, invertebrates, plants, and bacteria (Liu and Gross, 1996). Mammalian NOS (EC 1.14.13.39) has been extensively studied, and is known to consist of three isoforms: neuronal (nNOS), endothelial (eNOS), and inducible (iNOS; Knowles and Moncada, 1994). These isoforms differ in their structure, occurrence, and domain architecture, thus each displays distinctive features and performs specific functions in vivo (Knowles and Moncada, 1994). However, with the remarkable exception of Gram-negative bacteria, bacterial NOS enzymes lack reductase domains and require a supply of suitable reductants to produce NO (Sudhamsu and Crane, 2009). NOS has been comprehensively studied in vertebrates (Bogdan, 2001). To date, few crustacean NOS proteins have been biochemically characterized (Wu et al., 2013), although some investigations of the multiple functions of these enzymes in invertebrates have been published. In vertebrates, NOS is involved in several disparate processes, and this may also be the case in invertebrates (Labbé et al., 2009). NOS has been cloned and characterized in crab (McDonald et al., 2011), shrimp (Yao et al., 2010), and lobster (Rodríguez-Ramos et al., 2010). An earlier study showed that NOS in rats is a mediator in the female and male reproductive tracts (Rosselli et al., 1995). In rat males, androgen influences NOS activity in any tissue (Garban et al., 1995). Whereas, in female rat NO plays an important role in inducing ovulation and in causing luteolysis (McCann and Rettori, 1996). In addition, Buhimschi et al. (1996) suggested that NO appears to have an important role in the maintenance of sperm motility. Thus, it may be useful as another indicator of fertility potential. However, no reports yet exist concerning the function and specific role of NOS in the formation of invertebrate sex organs in general, and in Macrobrachium nipponense in particular. Most studies of crustacean NOS have focused on its relationship to the immune system. Therefore, in the present study, we investigated NOS in M. nipponense to assess its influence on sex determination and reproductive mechanisms.

Genetics and Molecular Research 15 (3): gmr.15038541 
The androgenic gland (AG) is an endocrine organ exclusive to male crustaceans and present in most such species, including the blue swimming crab Callinectes sapidus (Cronin, 1947). The successful removal of gonads and implantation of those of the opposite sex, resulting in the feminization or masculinization of the manipulated animal was demonstrated in amphipods in the 1950s. Subsequently, the AG has been confirmed as having a key role in crustacean sexual differentiation, determining male primary and secondary sexual characteristics (Abdu et al., 2002).

M. nipponense (Crustacea; Decapoda; Palaemonidae), more commonly known as the oriental river prawn, is a commercial freshwater prawn broadly distributed across different countries especially Asian ones, including China (Cai and Ng, 2002). M. nipponense is one of the main species cultured by Chinese inland fisheries and is of significant economic importance $(\mathrm{Fu}$ et al., 2012). The annual production of farmed oriental river prawn approximates 20 billion tons (Bureau of Fisheries, Ministry of Agriculture, 2014). Although previous studies have examined M. nipponense testes complementary DNA (cDNA) libraries and the AG transcriptome (Qiao et al., 2012; Jin et al., 2013), insufficient information regarding sex determination and differentiation-related genes is available for this species. It is known that males grow faster and accumulate more weight by the time of harvesting compared to females in many Macrobrachium species, including M. nipponense (Jin et al., 2013). In addition, sexual precocity (i.e., early sexual maturity) has become problem at cultured stocks, resulting in a reduction in market value (Qiao et al., 2012). Therefore, establishing effective ways to produce all-male populations through elucidation of the genetic mechanism behind M. nipponense development is vital to close the aquaculture industry production gap. Currently, male sexual differentiation-related genes in this organism are poorly understood and require further study to clarify the means by which M. nipponense sex is determined. Jin et al. (2013) identified NOS as a novel candidate gene and significantly expressed in the AG. Moreover, these authors suggested that it may play an important role in the sex-determination mechanism of the oriental river prawn. No reports have yet been published describing the cloning and expression profiling of AG NOS for the investigation of its potential role in $M$. nipponense sex determination. Therefore, in the present study, we cloned the full-length open reading frame (ORF) of NOS from the M. nipponense AG transcriptome, and characterized its expression profile in various tissues and at different developmental stages using real-time quantitative polymerase chain reaction (RT-qPCR). The highest level of NOS expression was found in the AG, and at 10 days post-larvae (PL), the critical organ formation stage. The findings presented here provide insight into our fundamental understanding of NOS as a sex differentiation gene in M. nipponense and other crustaceans, and will be useful in developing a strategy for sex control in M. nipponense aquaculture.

\section{MATERIAL AND METHODS}

\section{Experimental animals and tissue collection}

Healthy prawns (3.5-4.5 g) were purchased from Lake Tai in Wuxi, China $\left(120^{\circ} 13^{\prime} 44^{\prime \prime} \mathrm{E}\right.$, $\left.31^{\circ} 28^{\prime} 22^{\prime \prime} \mathrm{N}\right)$. Adults were kept under laboratory breeding conditions at $23^{\circ} \mathrm{C}$ and acclimated to the laboratory facility for 3 days in a 500-L tank containing aerated freshwater. For NOS cloning and tissue-specific expression measurements, various adult tissues, including those of the intestine, hepatopancreas, muscle, brain, gill, heart, eyestalk, testis, ovary, nerve cord, and AG were collected from at least 10 pieces of prawn, each with a wet weight of 2.3-

Genetics and Molecular Research 15 (3): gmr.15038541 
4.6g, and immediately preserved in liquid nitrogen before being stored at $-80^{\circ} \mathrm{C}$ prior to RNA extraction. Prawns at different developmental phases, including five embryonic, four larval, and four PL stages, were collected from the genetic breeding laboratory of the Freshwater Fisheries Research Center breeding room. After the spawning of gravid females, prawns of each embryonic stage (cleavage, blastula, gastrula pre-nauplius, pre-zoea), four larval stages (larvae were collected every 3 days), and four PL stages (PL were collected every 5 days from day 1-15) were collected and examined using an Olympus (Tokyo, Japan) SZX16 microscope. Developmental stage was determined based on morphological characters and the criteria of Chen et al. (2012). Samples were washed with 1X $0.01 \mathrm{M}$ phosphate-buffered saline, placed in liquid nitrogen, and stored at $-80^{\circ} \mathrm{C}$ until processing to preserve quality.

\section{RNA extraction and cDNA synthesis}

Total RNA was extracted from prawns of each developmental stage and the tissues of at least 10 adults using TRIzol reagent (Invitrogen, Waltham, MA, USA), and treated with RNase-free DNase I (TaKaRa, Dalian, China) following the manufacturer protocol, to denature any genomic DNA. Total RNA concentration and quality were determined by ultraviolet light absorbance at $260 \mathrm{~nm}\left(\mathrm{~A}_{260}\right)$, the $\mathrm{A}_{260} / \mathrm{A}_{280}$ ratio, and denaturing agarose gel electrophoresis. First-strand cDNA was synthesized using a Moloney murine leukemia virus reverse transcriptase kit (TaKaRa, Kusatsu, Japan). The reverse transcribed cDNA was stored at $-20^{\circ} \mathrm{C}$ until needed for RT-qPCR (Qiao et al., 2012).

\section{NOS gene 5'- and 3'-random amplification of cDNA ends (RACE)}

The NOS expressed sequence tag obtained from the M. nipponense AG transcriptome (Jin et al., 2013) was used to design four gene-specific primers (Table 1). The cloning of M. nipponense NOS (MnNOS) cDNA was achieved by 5' and 3'-RACE using the 5'- and 3' Full RACE Kit (TaKaRa) following the manufacturer protocols. The 5'-RACE primer sets consisted of the two gene-specific primers GSP1 and GSP2, and the universal primers 5' RACE OUT and 5' RACE INN (Table 1). For 3'-RACE, the two gene-specific primers GSP3 and GSP4, and the universal primers 3' RACE OUT and 3' RACE INN were used (Table 1). PCR fragments were subjected to electrophoresis on $1.2 \%$ agarose gels to compare product lengths based on the de novo transcriptome library sequences. Amplified cDNA fragments were inserted into the pMD18-T vector for cloning, and sequenced using M13 forward and reverse primers. The resulting sequences were confirmed and subjected to cluster analysis using BLASTn from National Center for Biotechnology Information (NCBI) tool.

\section{Analyses of nucleotide and deduced amino acid sequences}

Based on the BLASTnx algorithm, the sequence from the M. nipponense AG transcriptome was found to be highly homologous to members of the NOS gene family in Penaeus monodon, Litopenaeus vannamei, and Marsupenaeus japonicus. The ORF of this sequence was identified using the Translate tool (http://web.expasy.org/translate/) and the NCBI BLASTn and BLASTnx programs (http://www.ncbi.nlm.nih.gov/BLAST). Molecular weights (MWs) and isoelectric points (pIs) of deduced amino acid sequences were analyzed with the Compute pI/Mw tool (http://web.expasy.org/compute_pi/), while functional domain

Genetics and Molecular Research 15 (3): gmr.15038541 
analysis was performed using Genomic SMART (http://smart.embl.de/smart/set_mode. cgi?GENOMIC=1). Multiple sequence alignment was conducted with DNAMAN and MEGA 5.1 (Tamura et al., 2011), was used to generate a neighbor-joining (NJ) phylogenetic tree based on vertebrate and invertebrate amino acid sequences (Table 2).

Table 1. Nucleotide sequences of primers used for Macrobrachium nipponense nitric oxide synthase gene (MnNOS) cloning and expression analysis.

\begin{tabular}{|c|c|c|}
\hline & Sequence (5' to $\left.3^{\prime}\right)$ & Name \\
\hline \multicolumn{3}{|l|}{ Primers for 5'-RACE PCR } \\
\hline MnNOS 5' GSP primer 1 & TCTTCTGGCACATCTTGGTGAA & GSP1 \\
\hline MnNOS 5' GSP primer 2 & TTCAGATTCAGCTCCTCGAACC & GSP2 \\
\hline \multicolumn{3}{|l|}{ Primers for 3'-RACE PCR } \\
\hline MnNOS 3' GSP primer 1 & CGAGACAAGATCGAGCTGTTCGT & GSP3 \\
\hline MnNOS 3' GSP primer 2 & GAAGATGTCCTCTATCTCTCAAG & GSP4 \\
\hline \multicolumn{3}{|l|}{ Full RACE Kit primers } \\
\hline 3' RACE OUT & ATCCGACGAAGACAAACTCTACC & \\
\hline 3' RACE IN & CGCGGATCCTCCACTAGTGATTTCACTATAGG & \\
\hline 5' RACE OUT & CTCCACAATGGGCTTTTTCATCC & \\
\hline 5' RACE IN & CGCGGATCCACAGCCTACTGATGATCAGTCGATG & \\
\hline \multicolumn{3}{|c|}{ Primers for RT-qPCR analysis } \\
\hline MnNOS F primer & TCACATGGAACAAACTGCATGTG & RT-F1 \\
\hline MnNOS R primer & CGTACCCGGCGAAGGCGATCAGC & RT-R1 \\
\hline$\beta$-Actin 5' primer & TATGCACTTCCTCATGCCATC & $\beta$-ActinF \\
\hline$\beta$-Actin 3' primer & AGGAGGCGGCAGTGGTCAT & $\beta$-ActinR \\
\hline
\end{tabular}

$\mathrm{RACE}=$ random amplification of complementary DNA ends; $\mathrm{PCR}=$ polymerase chain reaction; RT-qPCR $=$ realtime quantitative PCR; $\mathrm{F}$ = forward; $\mathrm{R}=$ reverse.

Table 2. Nitric oxide synthase (NOS) sequences from the National Center for Biotechnology Information used for multiple alignment, homology assessment, and phylogenetic analysis.

\begin{tabular}{|c|c|c|c|}
\hline Species & Name/accession No. & Order/Family & Identity (\%) \\
\hline Limulus polyphemus & iNOS/XP_013781426.1 & Xiphosura/Limulidae & 34 \\
\hline Homo sapiens & $\begin{array}{l}\text { nNOS/NP_001191147.1 } \\
\text { eNOS/BAA05652.1 } \\
\text { iNOS/NP_000616.3 }\end{array}$ & Primates/Hominidae & $\begin{array}{l}30 \\
33 \\
34\end{array}$ \\
\hline Mus musculus & $\begin{array}{l}\text { nNOS/NP_032738.1 } \\
\text { eNOS/NP_032739.3 } \\
\text { iNOS/NP_035057.1 }\end{array}$ & Rodentia/Muridae & $\begin{array}{l}27 \\
32 \\
33\end{array}$ \\
\hline Danio rerio & nNOS/XP_005165110.1 & Cypriniformes/Cyprinidae & 29 \\
\hline Chrysochloris asiatica & iNOS/XP_006874299.1 & Afrosoricida/Chrysochloridae & 35 \\
\hline Myotis davidii & iNOS/ELK24792.1 & Chiroptera/Vespertilionidae & 32 \\
\hline Sus scrofa & iNOS/NP_001137162.1 & Artiodactyla/Suidae & 41 \\
\hline Physeter catodon & iNOS/XP_007109277.1 & Cetartiodactyla/Physeteridae & 30 \\
\hline Orcinus orca & iNOS/XP_012387409.1 & Cetartiodactyla/Delphinidae & 33 \\
\hline Carcinus maenas & NOS/ACY56317.1 & Decapoda/Portunidae & 41 \\
\hline Scylla paramamosain & NOS/CCC18661.1 & Decapoda/Portunidae & 44 \\
\hline Gecarcinus lateralis & NOS/AAT46681.1 & Decapoda/Gecarcinidae & 43 \\
\hline Panulirus argus & NOS/ACZ60615.1 & Decapoda/Palinuridae & 42 \\
\hline Marsupenaeus japonicus & NOS/BAI67609.1 & Decapoda/Penaeidae & 45 \\
\hline Litopenaeus vannamei & NOS/ADD63793.1 & Decapoda/Penaeidae & 45 \\
\hline Penaeus monodon & NOS/ACJ54486.1 & Decapoda/Penaeidae & 45 \\
\hline Fenneropenaeus chinensis & NOS/AFJ74715.1 & Decapoda/Penaeidae & 44 \\
\hline Halyomorpha halys & NOS/XP_014272116.1 & Hemiptera/Pentatomidae & 42 \\
\hline Drosophila melanogaster & NOS/NP_523541.2 & Diptera/Drosophilidae & 38 \\
\hline Apis mellifera & NOS/NP_001012980.1 & Hymenoptera/Apidae & 40 \\
\hline Bombus impatiens & NOS/XP_003485294.1 & Hymenoptera/Apidae & 39 \\
\hline Monomorium pharaonis & NOS/XP_012524269.1 & Hymenoptera/Formicidae & 40 \\
\hline Harpegnathos saltator & NOS/EFN84471.1 & Hymenoptera/Formicidae & 38 \\
\hline Macrobrachiumnipponense & NOS/KU382528 & Decapoda/Palaemonidae & 100 \\
\hline
\end{tabular}

iNOS $=$ inducible NOS; nNOS = neuronal NOS; eNOS = endothelial NOS.

Genetics and Molecular Research 15 (3): gmr.15038541 


\section{Expression of MnNOS in different adult tissues and developmental stages}

Transcription of the MnNOS gene in various embryonic and PL stages and several adult tissues was measured by SYBR Green RT-qPCR analysis using an iCycler iQ5 RealTime System (Bio-Rad, Hercules, CA, USA), with the $\beta$-actin gene as an internal control. The specificity of the MnNOS and $\beta$-actin primers (Table 1) was verified by sequencing the PCR products. Three samples were collected for each developmental stage and tissue type, and each sample was analyzed in triplicate. Each $25-\mu \mathrm{L}$ PCR comprised $1 \mu \mathrm{L}$ cDNA (50 ng), $10 \mu \mathrm{L}$ SsoFast EvaGreen Supermix (Bio-Rad), $0.5 \mu \mathrm{L} 10 \mu \mathrm{M}$ gene-speciðc forward and reverse primers (Table 1), and $13 \mu \mathrm{L}$ diethyl pyrocarbonate-treated water. The reaction mixture was initially incubated for $30 \mathrm{~s}$ at $95^{\circ} \mathrm{C}$ to activate the Hot Start Taq DNA polymerase, before 40 cycles of 10 -s denaturation at $95^{\circ} \mathrm{C}$ and 10 -s extensions at $60^{\circ} \mathrm{C}$. Melting curve analysis was performed from $65^{\circ}-95^{\circ} \mathrm{C}$ in $10-\mathrm{s} 0.5^{\circ} \mathrm{C}$ increments to verify the amplification of a single product (Zhang et al., 2013).

\section{Statistical analysis}

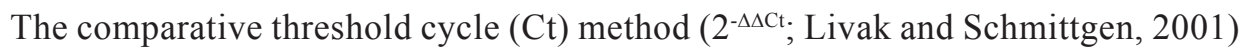
was used to analyze MnNOS expression, which is reported as mean relative mRNA level \pm standard error. Data were subjected to one-way analysis of variance, and P values smaller than 0.05 were considered statistically significant.

\section{RESULTS}

\section{Characterization of full-length $\mathrm{MnNOS}$}

The sequence obtained by 5'- and 3'-RACE was $3716 \mathrm{bp}$ in length, representing the full-length MnNOS cDNA. It contained an ORF of $3447 \mathrm{bp}$, encoding a polypeptide of 1148 amino acids. The corresponding protein had an estimated MW of $129.209 \mathrm{kDa}$ and a $\mathrm{pI}$ of 7.12. Untranslated regions of 130 and $139 \mathrm{bp}$ were identified at the 5'- and 3'-end, respectively, and a complete poly (A) tail was present. The ORF begins with an ATG start codon and contains a TGA stop codon at its 3'-end (Figure 1). The cDNA sequence incorporating the full length MnNOS ORF has been deposited in GenBank under accession No. KU382528 (Figure 1). Homology searches using the predicted MnNOS amino acid sequence were performed using the BLASTp algorithm on the NCBI web site.

Prediction of MnNOS domains by SMART based on the deduced amino acid sequence revealed an NOS domain at positions 62 to 424 . In addition, a flavodoxin 1 domain was found at positions 474 to 680 , a flavin adenine dinucleotide (FAD)-binding domain at positions 776 to 945 , and an NAD-binding domain at positions 977 to 1054 (Figure 1). The complete domain structure was compared with those of other NOS enzymes from different species to determine the degree of similarity across evolutionary distance. These domains were highly conserved among NOS homologs, from crustaceans to vertebrates, including humans and fish (Figure 2).

Genetics and Molecular Research 15 (3): gmr.15038541 


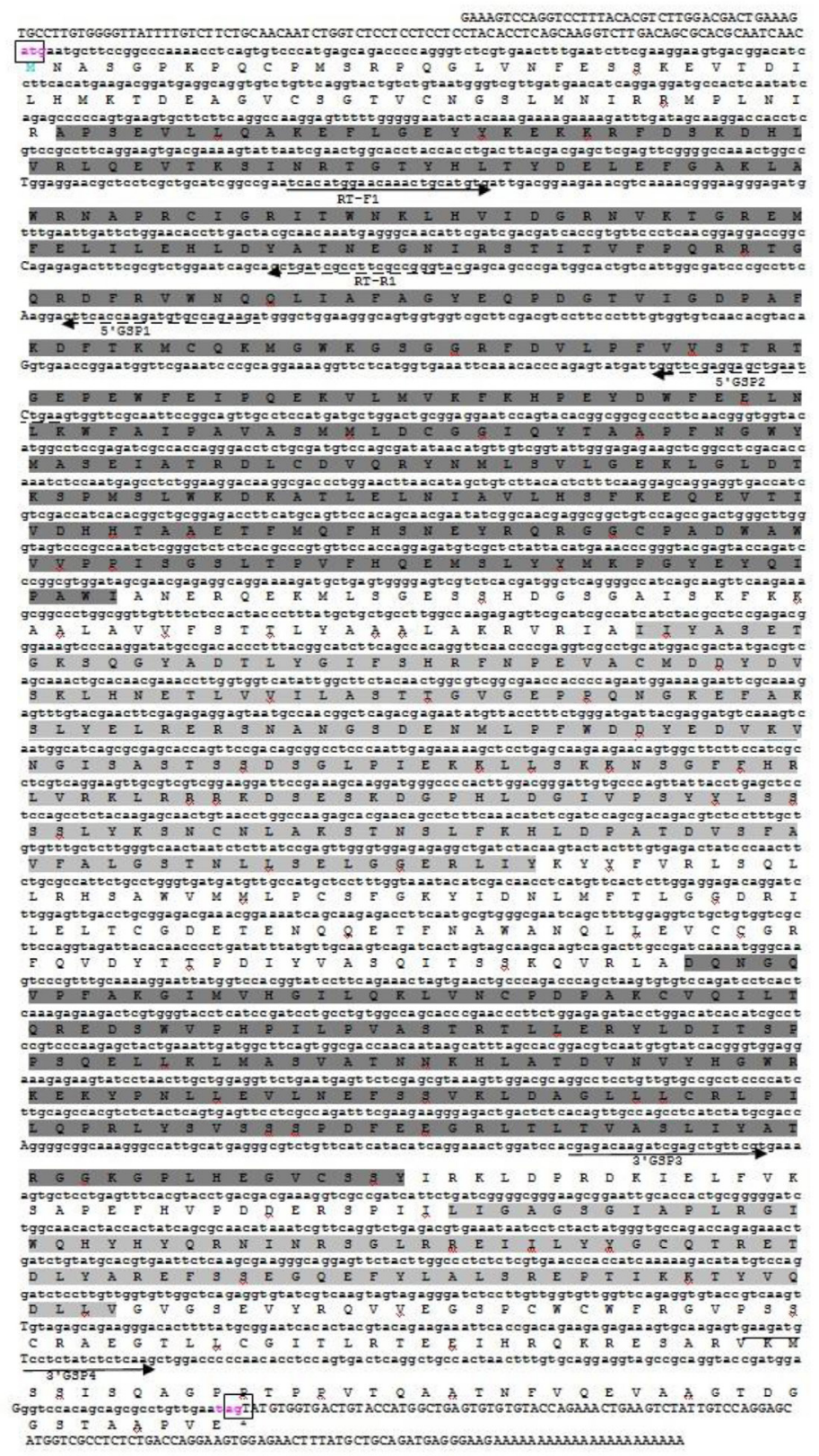

Figure 1. Complete nucleotide and deduced amino acid sequence of Macrobrachium nipponense nitric oxide synthase (NOS). Bold letters in boxes indicate start (atg) and stop (tag) codons and the polyadenylation signal sequence. NOS (amino acids 62-424), flavodoxin 1 (474-680), flavin adenine dinucleotide-binding (776-945), and nicotinamide adenine dinucleotide-binding (977-1054) domains are indicated (light gray highlighting). Primers used for real-time quantitative polymerase chain reaction are represented using broken lines and bold letters. Solidline arrows and bold letters signify the locations and directions of the sequence-specific nested primers used for 5'- and 3'-RACE. This sequence has been deposited in GenBank under accession No. KU382528.

Genetics and Molecular Research 15 (3): gmr.15038541 


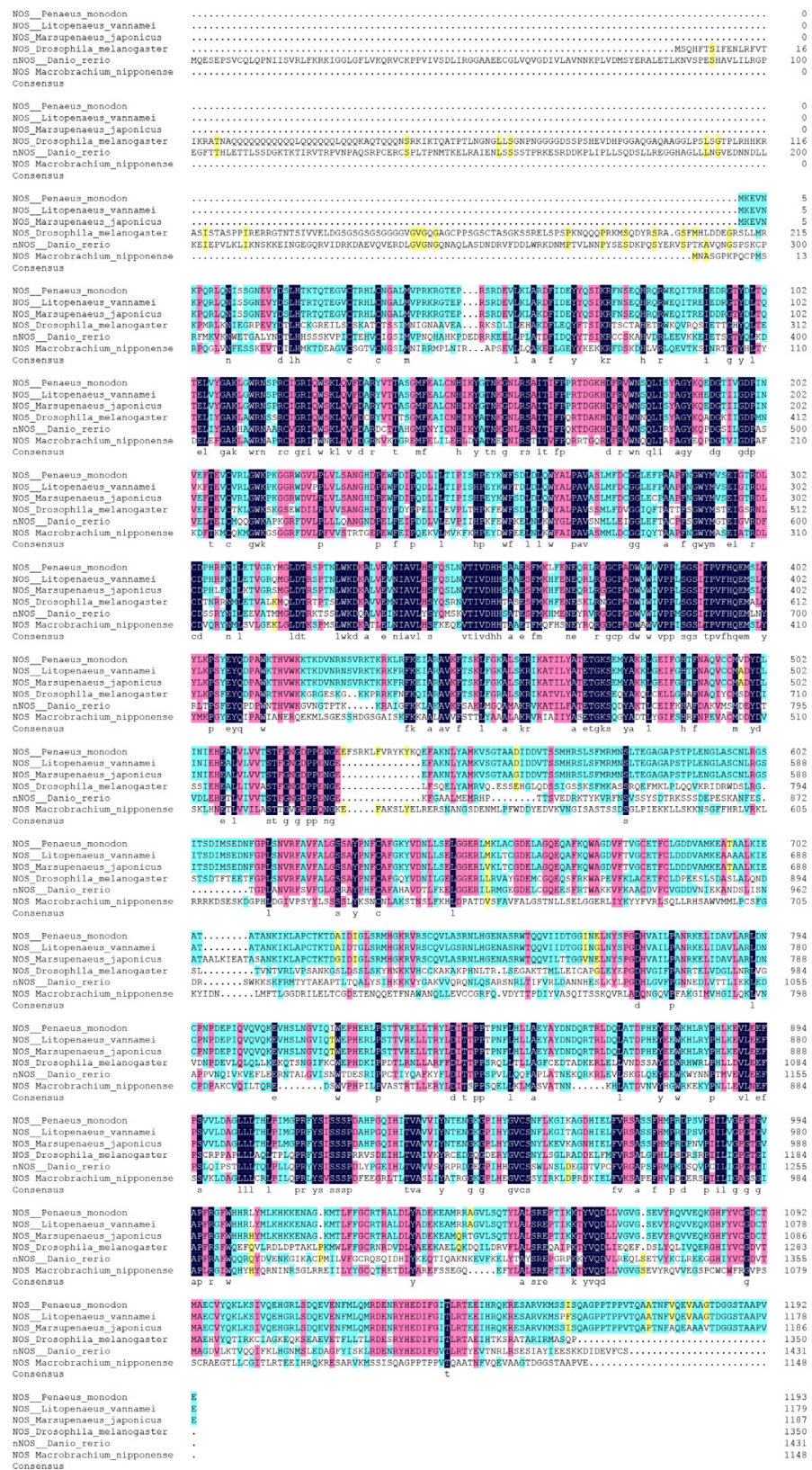

Figure 2. Alignment of the deduced nitric oxide synthase (NOS) amino acid sequence of Macrobrachium nipponense (accession No. KU382528) with those of other species, details of which are summarized in Table 2. Identical residues are highlighted using a dark background, while similar amino acids are indicated in pink. Insertions (...) were added to maximize sequence identity. NOS enzymes from Penaeus monodon (accession No. ACJ54486.1), Litopenaeus vannamei (ADD63793.1), Marsupenaeus japonicus (BAI67609.1), Drosophila melanogaster (NP_523541.2), and Danio rerio (XP_005165110.1) are included. Sequences were aligned using DNAMAN (Lynnon Biosoft, San Ramon, CA, USA).

Genetics and Molecular Research 15 (3): gmr.15038541 


\section{Phylogenetic analysis of MnNOS}

Twenty-eight NOS sequences from crustaceans, fish, and mammals were used to construct a phylogenetic tree. The deduced NOS amino acid sequence from M. nipponense demonstrated the closest phylogenetic relationship with those of other crustacean species. Inferred protein sequences of three types of invertebrate and vertebrate (nNOS, eNOS, and iNOS) were compared (Figure 3).

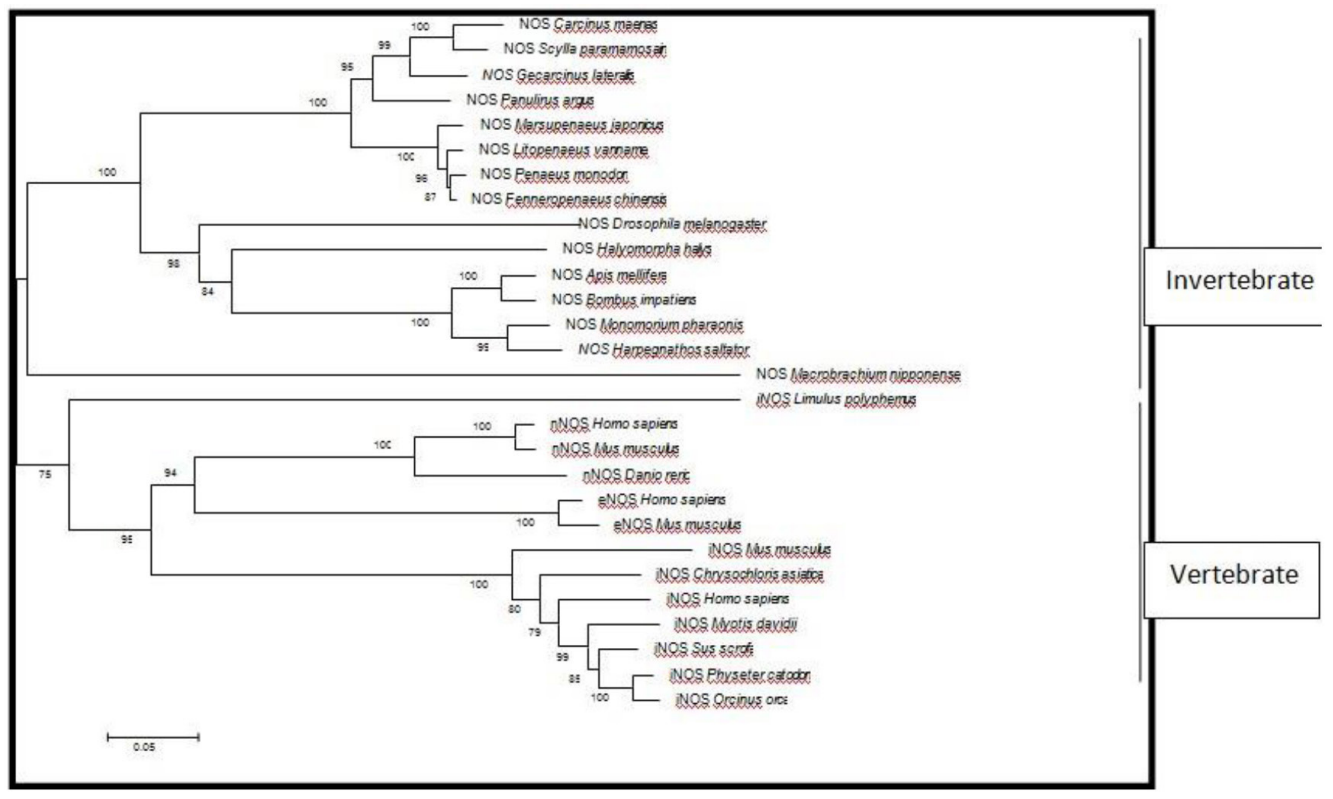

Figure 3. Phylogenetic tree of 28 nitric oxide synthase (NOS) proteins from crustaceans, fish, insects, and mammals. Complete amino acid sequences were aligned using DNAMAN, and a neighbor-joining tree was constructed with MEGA 4.1. Bootstrap analysis was performed using 1000 replicates to test relative support for each cluster. Names and accession Nos. are as follows: Limulus polyphemus (iNOS, XP_013781426.1), Homo sapiens (nNOS, NP_001191147.1; iNOS, NP_000616.3; eNOS, BAA05652.1), Mus musculus (nNOS, NP_032738.1; iNOS, NP_035057.1; eNOS, NP_032739.3), Danio rerio (nNOS, XP_005165110.1), Chrysochloris asiatica (iNOS, XP_006874299.1), Myotis davidii (iNOS, ELK24792.1), Sus scrofa (iNOS, NP_001137162.1), Physeter catodon (iNOS, XP_007109277.1), Orcinus orca (iNOS, XP_012387409.1), Carcinus maenas (NOS, ACY56317.1), Scylla paramamosain (NOS,CCC18661.1), Gecarcinus lateralis (NOS, AAT46681.1), Panuli rusargus (NOS, ACZ60615.1), Marsupenaeus japonicus (NOS, BAI67609.1), Litopenaeus vannamei (NOS, ADD63793.1), Penaeus monodon (NOS, ACJ54486.1), Fenneropenaeus chinensis (NOS, AFJ74715.1), Drosophila melanogaster (NOS, NP_523541.2), Halyomorpha halys (NOS, XP_014272116.1), Apis mellifera (NOS,NP_001012980.1), Bombus impatiens (NOS, XP_003485294.1), Monomorium pharaonis (NOS,XP_012524269.1), Harpegnathos saltator (NOS, EFN84471.1), and Macrobrachium nipponense (NOS, KU382528). Information regarding these sequences is summarized in Table 2. iNOS = inducible NOS; nNOS = neuronal NOS; eNOS = endothelial NOS.

\section{Tissue expression of MnNOS mRNA}

The expression of MnNOS in various tissues was examined by RT-qPCR. MnNOS transcription was detected in gill, muscle, brain, intestine, eyestalk, testis, ovary, heart, hepatopancreas, AG, and nerve cord samples. MnNOS was relatively abundant in the 
hepatopancreas and muscle, whereas only trace levels were detectable in the heart, gonads, and nerve cord. The highest expression was observed in the AG $(\mathrm{P}<0.05$; Figure 4$)$.

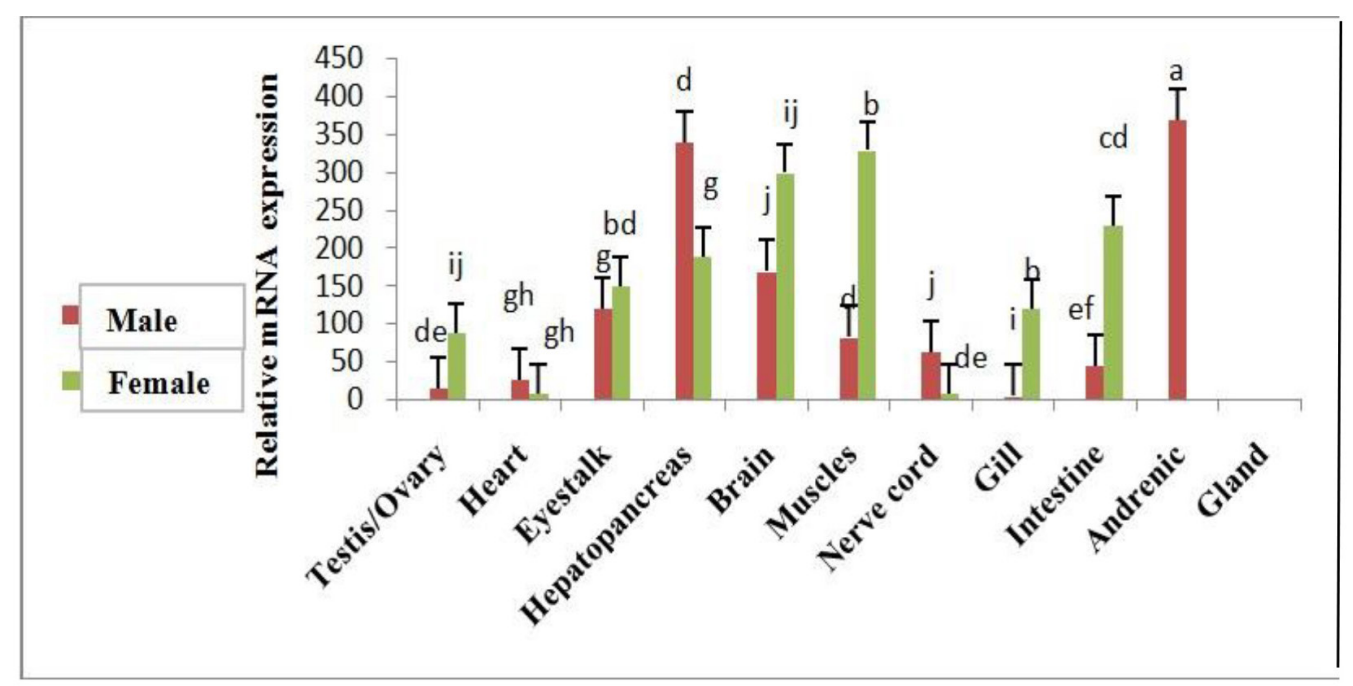

Figure 4. Distribution of nitric oxide synthase mRNA in the different tissues of adult male and female Macrobrachium nipponense. Data are reported as mean fold changes (means \pm standard errors of the mean; $\mathrm{N}=3$ ). Statistical significance was calculated by one-way analysis of variance and multiple comparison tests.

\section{Expression of MnNOS mRNA during different developmental stages of prawn embryos, larvae, and PL}

RT-qPCR was applied to investigate the expression of MnNOS throughout development. MnNOS mRNA could be detected at all stages, and its transcription underwent two increases during certain larva land PL phases. The first occurred at larval stage L13 after hatching and the second at 10 days PL (PL10), at which point MnNOS expression was at its highest $(\mathrm{P}<0.01$; Figure 5).

\section{DISCUSSION}

NOS is an important enzyme due its specific role in synthesizing NO by catalyzing the conversion of L-arginine to L-citrulline, accompanied by the oxidation of NADPH (Yao et al., 2010). Consequently, it is crucial to the physiological functioning of NO. Many studies have confirmed that NOS has beneficial and versatile roles in the microvascular, neural, and immune systems (Figueroa et al., 2001). NOS sequences have been examined in several crustaceans (Rodríguez-Ramos et al., 2010; Yao et al., 2010; McDonald et al., 2011), but that of M. nipponense remains unknown. In the current study, we cloned $N O S$ and demonstrated its elevated expression in the M. nipponense AG, suggesting that it is of great importance in male sexual differentiation in this species.

The full-length MnNOS cloned in this investigation comprised a complete ORF of $3447 \mathrm{bp}$, encoding a 1148-amino acid protein with an estimated MW of $129.209 \mathrm{kDa}$ and a $\mathrm{pI}$

Genetics and Molecular Research 15 (3): gmr.15038541 


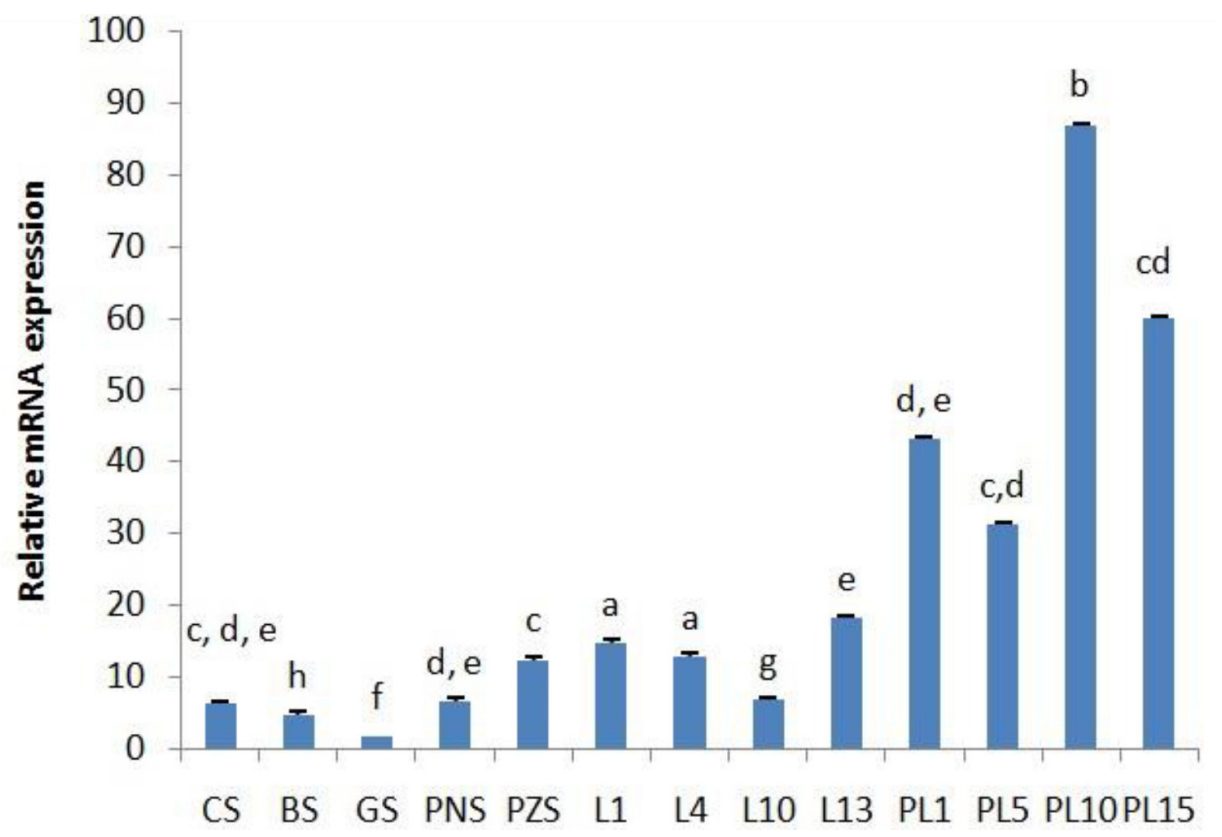

Figure 5. Expression of the Macrobrachium nipponense nitric oxide synthase gene at different development stages. Data are reported as means \pm standard errors of the mean, based on three samples of each embryonic, larval (L), and post-larval (PL) stage. Bars with different letters are significantly different $(\mathrm{P}<0.05)$. $\mathrm{CS}=$ cleavage stage; $\mathrm{BS}$ = blastula stage; GS = gastrula stage; $\mathrm{PNS}$ = pre-nauplius stage; PZS = pre-zoea stage; $\mathrm{L} 1$ = first-day larvae after hatching; PL1 = first-day post-larvae after metamorphosis.

of 7.12. Untranslated regions of 130 and $139 \mathrm{bp}$ were detected at the 5'- and 3'-end, respectively, in addition to a complete poly(A) tail (Figure 1). Structural analysis of the MnNOS amino acid sequence using the SMART program revealed its organization to be remarkably similar to that of other crustacean NOS proteins. It includes four principal domains: a highly conserved N-terminal NOS domain from position 62 to 424, vital for the production of NO; a flavodoxin 1 domain between positions 474 and 680; a FAD-binding domain at position 776 to 945 ; and a C-terminal NAD-binding domain homolog encompassing residues 977 to 1054 that is functionally important in various electrontransport systems (Figure 1). Furthermore, multiple sequence alignment showed that the deduced MnNOS amino acid sequence is very similar to those of vertebrate (Wang et al., 2001) and invertebrate (Hoskins et al., 2007; McDonald et al., 2011) NOS enzymes (Figure 2). Considering such homology, we speculate that NOS function in M. nipponense is typical of this enzyme type, and as in other organisms, MnNOS may affect multiple roles.

In the present study, we constructed an NJ phylogenetic tree based on the amino acid sequences of 28 NOS enzymes (including nNOS, eNOS, and iNOS) from invertebrates (crustaceans and arthropods) and vertebrates (fish and mammals). MnNOS formed a distinct cluster with other invertebrate NOS proteins, demonstrating their close taxonomic relationship compared with vertebrate sequences, and indicating that NOS is highly conserved across these organisms. The alignment also showed that MnNOS shared $45 \%$ identity with the P. monodon, L. vannamei, and M. japonicus NOS protein family, but only low identity with Mus musculus 
sequences $(27 \%$ with murine nNOS). Thus, compared to vertebrate enzymes, the MnNOS sequence exhibited a relatively high level of identity with crustacean NOSs (Figure 3). This evolutionary relationship implies that, with the exception of iNOS produced by the arthropod Limulus polyphemus, different isoforms of this enzyme may not be found in invertebrates, and this lineage may have inherited only on eNOS type, as in mollusks (Andreakis et al., 2011), the mud crab Scylla paramamosain (Li et al., 2012), and the Zhikong scallop Chlamys farreri (Jiang et al., 2013). Furthermore, the observed connections between these groups might reflect taxonomic relationships, and appear to show that although MnNOS clustered with invertebrate NOS enzymes, it was not closely related to that of any species examined. Given the lack of similarity to other crustacean sequences, this NOS may be exclusive to $M$. nipponense and may display unique features (Figure 3). The activity of this enzyme needs further investigation.

In the present study, NOS was expressed in all of the tissues tested, consistent with previous studies in which this gene has been shown to be widely expressed in insect, mammalian, and crustacean tissues, and to regulate a variety of physiological processes (Kim et al., 2004). Furthermore, most prior reports have confirmed the involvement of NO in metabolism, growth, cell proliferation, development, and neurogenesis in vertebrates, insects, and mollusks, verifying the broad role of NOSs in the microvascular, neural, and immune systems (Kuzin et al., 1996; Andreakis et al., 2011; Hampton et al., 2015). Furthermore, NO in rat has additional functions as it appears to be found in all parts of the male reproductive system as well and seems to play a role in testicular, epididymal and vas deferens function. Moreover, in female reproductive tract, it relaxes uterine muscle via cGMP and contracts it via prostaglandins, and it is expression was increased in the cervix, and decreased in the uterus, during labour and preterm labour (Buhimschi et al., 1996). NO also seems to be involved in pre-eclamptic conditions and pregnancy-related hypertension (Buhimschi et al., 1996). These findings are in consistency with our RT-qPCR result which revealed that MnNOS level was expressed in all detected tissues including gonads (testis and ovary), hepatopancreas, gill, eyestalk, brain, intestine, muscles, nerve cord and AG which represent the significantly higher expression in M. nipponense. Additionally, with the result in scallop C. farreri, the highest expression of NOS was found in the gonads (Jiang et al., 2013). Kim et al. (2004) found NOS to be expressed in nerve ganglia, Y-organ, gill and gonad of the tropical land crab, Gecarcinus lateralis. And McDonald et al. (2011) found high expression of NOS in Y-organs of the green shore crab Carcinus maenas. In the Pacific white shrimp L. vannamei and the mud crab $S$. paramamosain, expression has been detected in the hepatopancreas (Yao et al., 2010; Li et al., 2012), whereas in the kuruma shrimp M. japonicus, it has been observed in the gills and brain (Inada et al., 2010). In addition, iNOS is expressed in hemocytes of the spiny lobster Panulirus argus (Rodríguez-Ramos et al., 2010). Identification of the expression of this interesting molecule in the AG may provide insights into the genetic framework behind sex determination in $M$. nipponense. Moreover, these findings collectively expand our current understanding of $M$. nipponense and crustacean sexual differentiation. Consequently, MnNOS may prove significant in efforts to manipulate the $M$. nipponense reproductive system to produce all-male populations. Here, the NOS gene was expressed in all tested tissues, indicating that it may perform versatile biological functions in this organism. Furthermore, the AG could play an important role in synthesizing NOS in M. nipponense. A more detailed assessment of MnNOS activity is needed.

Interestingly, $M n N O S$ was expressed throughout development, from early embryonic

Genetics and Molecular Research 15 (3): gmr.15038541 
to late PL stages. Expression levels in the blastula and gastrula are crucial, as these are key stages of cell differentiation and organ formation (Zhang et al., 2010). An earlier finding of Herrero et al. (1997) demonstrated that the presence of NOS in spermatazoa induces sperm motility, which implies its multiple role to promote reproduction throughout all levels in the organism, therefore, NO considered as a sexual gas (McCann and Rettori, 1996). In this study, the expression of NOS decreased during the initial larval stages, reaching its lowest level at L10. Metamorphosis takes place at this point, during which the transcription of most genes decreases, including NOS. RT-qPCR measured the highest expression at stage PL10. In our previous study, we found that M. nipponense primordial germ cells (PGCs) appear between stages PL10 and PL15, together with external sexual characteristics (Zhang et al., 2013). Thus, the current results are consistent with these observations, suggesting that MnNOS may be involved in organ formation. Significant MnNOS transcription during PL10 may coincide with the development of PGCs and external sexual attributes in M. nipponense. Based on these findings and the result of Herrero et al. (1997) and McCann and Rettori (1996), we speculated that this gene may be involved in sex differentiation in this organism. Furthermore, the expression of MnNOS across different stages of development might indicate that it also plays an important role in this process as well as in the developmental stages.

In conclusion, we generated a full-length clone of the MnNOS gene, a novel NOS sequence, and investigated its transcriptional patterns in different tissues and developmental stages of M. nipponense. From this, we can infer that the presence of MnNOS during embryonic and PL stages may have an important influence on external sexual development and determination of male sex in this organism. Therefore, MnNOS could serve an important purpose in producing all-male cultures of these prawns. Moreover, the protein encoded by this gene might fulfill varied biological roles in M. nipponense. Further detailed investigations should be carried out to elucidate the functions of MnNOS.

\section{Conflicts of interest}

The authors declare no conflict of interest.

\section{ACKNOWLEDGMENTS}

Reserach supported by the National Natural Science Foundation of China (grant \#31572617), the National Science \& Technology Supporting Program of the 12th FiveYear Plan of China (\#2012BAD26B04), the Fund of Independent Innovation of Agricultural Sciences of Jiangsu Province [\#CX (15)1012-4], the three aquatic projects of Jiangsu Province (\#D2015-16), and the Wuxi Science and Technology Development Fund (\#CLE02N1514).

\section{REFERENCES}

Abdu U, Davis C, Khalaila I and Sagi A (2002). The vitellogenin cDNA of Cherax quadricarinatus encodes a lipoprotein with calcium binding ability, and its expression is induced following the removal of the androgenic gland in a sexually plastic system. Gen. Comp. Endocrinol. 127: 263-272. http://dx.doi.org/10.1016/S0016-6480(02)00053-9

Andreakis N, D'Aniello S, Albalat R, Patti FP, et al. (2011). Evolution of the nitric oxide synthase family in metazoans. Mol. Biol. Evol. 28: 163-179 http://dx.doi.org/10.1093/molbev/msq179.

Bogdan C (2001). Nitric oxide and the regulation of gene expression. Trends Cell Biol. 11:66e75.

Buhimschi I, Ali M, Jain V, Chwalisz K, et al. (1996). Differential regulation of nitric oxide in the rat uterus and cervix

Genetics and Molecular Research 15 (3): gmr.15038541 
during pregnancy and labour. Hum. Reprod. 11: 1755-1766. http://dx.doi.org/10.1093/oxfordjournals.humrep. a019481

Bureau of Fishery, Ministry of Agriculture (2009). Fisheries economic statistics. China Fishery Yearbook. China Agricultural Press, Beijing.

Cai Y and Ng PKL (2002). The freshwater palaemonid prawns (Crustacea: Decapoda: Caridea) of Myanmar. Hydrobiologia 487: 59-83. http://dx.doi.org/10.1023/A:1022991224381

Chen Y, Zhu Q, Chen H, Zhu XL, et al. (2012). The morphological and histological observation of embryonic development in the oriental river prawn Macrobrachium nipponense. Shanghai Hai Yang Da Xue Xue Baok 21: 33-40.

Cronin LE (1947). Anatomy and histology of the male reproductive system of Callinectes sapidus Rathbun. J. Morphol. 81: 209-239. http://dx.doi.org/10.1002/jmor.1050810205

Eddy FB (2005). Role of nitric oxide in larval and juvenile fish. Comp. Biochem. Physiol. A Mol. Integr. Physiol. 142: 221-230. http://dx.doi.org/10.1016/j.cbpb.2005.05.038

Figueroa XF, Martínez AD, González DR, Jara PI, et al. (2001). In vivo assessment of microvascular nitric oxide production and its relation with blood flow. Am. J. Physiol. Heart Circ. Physiol. 280: H1222-H1231.

Fu H, Sufei J and Yiwei X (2012). Current status and prospects of farming thegiant river prawn (Macrobrachium rosenbergii) and the oriental river prawn (Macrobrachium nipponense) in China. Aquacult. Res. 43: 993-998. http:// dx.doi.org/10.1111/j.1365-2109.2011.03085.x

Garban H, Marquez D, Cai L, Rajfer J, et al. (1995). Restoration of normal adult penile erectile response in aged rats by long-term treatment with androgens. Biol. Reprod. 53: 1365-1372. http://dx.doi.org/10.1095/biolreprod53.6.1365

Hampton BM, Schwartz SG, Brantley MA, Jr. and Flynn HW, Jr. (2015). Update on genetics and diabetic retinopathy. Clin. Ophthalmol. 9: 2175-2193.

Herrero MB, Viggiano JM, Pérez Martínez S and de Gimeno MF (1997). Evidence that nitric oxide synthase is involved in progesterone-induced acrosomal exocytosis in mouse spermatozoa. Reprod. Fertil. Dev. 9: 433-439. http://dx.doi. org/10.1071/R96044

Hoskins RA, Carlson JW, Kennedy C, Acevedo D, et al. (2007). Sequence finishing and mapping of Drosophila melanogaster heterochromatin. Science 316: 1625-1628. http://dx.doi.org/10.1126/science.1139816

Inada M, Mekata T, Sudhakaran R, Okugawa S, et al. (2010). Molecular cloning and characterization of the nitric oxide synthase gene from kuruma shrimp, Marsupenaeus japonicus. Fish Shellfish Immunol. 28: 701-711. http://dx.doi. org/10.1016/j.fsi.2010.01.010

Jiang Q, Zhou Z, Wang L, Wang L, et al. (2013). A scallop nitric oxide synthase (NOS) with structure similar to neuronal NOS and its involvement in the immune defense. PLoS One 8: e69158. http://dx.doi.org/10.1371/journal. pone. 0069158

Jin S, Fu H, Zhou Q, Sun S, et al. (2013). Transcriptome analysis of androgenic gland for discovery of novel genes from the oriental river prawn, Macrobrachium nipponense, using Illumina Hiseq 2000. PLoS One 8: e76840. http://dx.doi. org/10.1371/journal.pone.0076840

Kim HW, Batista LA, Hoppes JL, Lee KJ, et al. (2004). A crustacean nitric oxide synthase expressed in nerve ganglia, Y-organ, gill and gonad of the tropical land crab, Gecarcinus lateralis. J. Exp. Biol. 207: 2845-2857. http://dx.doi. org $/ 10.1242 /$ jeb. 01117

Knowles RG and Moncada S (1994). Nitric oxide synthases in mammals. Biochem. J. 298: 249-258. http://dx.doi. org/10.1042/bj2980249

Kubes P, Suzuki M and Granger DN (1991). Nitric oxide: an endogenous modulator of leukocyte adhesion. Proc. Natl. Acad. Sci. USA 88: 4651-4655. http://dx.doi.org/10.1073/pnas.88.11.4651

Kuzin B, Roberts I, Peunova N and Enikolopov G (1996). Nitric oxide regulates cell proliferation during Drosophila development. Cell 87: 639-649. http://dx.doi.org/10.1016/S0092-8674(00)81384-7

Labbé P, McTaggart SJ and Little TJ (2009). An ancient immunity gene duplication in Daphnia magna: RNA expression and sequence analysis of two nitric oxide synthase genes. Dev. Comp. Immunol. 33: 1000-1010. http://dx.doi. org/10.1016/j.dci.2009.04.006

Li S, Zhang Z, Li C, Zhou L, et al. (2012). Molecular cloning and expression profiles of nitric oxide synthase (NOS) in mud crab Scylla paramamosain. Fish Shellfish Immunol. 32: 503-512. http://dx.doi.org/10.1016/j.fsi.2011.12.002

Liu Q and Gross SS (1996). Binding sites of nitric oxide synthases. Methods Enzymol. 268: 311-324. http://dx.doi. org/10.1016/S0076-6879(96)68033-1

Livak KJ and Schmittgen TD (2001). Analysis of relative gene expression data using real-time quantitative PCR and the 2(-Delta Delta C(T)) Method. Methods 25: 402-408. http://dx.doi.org/10.1006/meth.2001.1262

McCann SM and Rettori V (1996). The role of nitric oxide in reproduction. Proc. Soc. Exp. Biol. Med. 211: 7-15. http:// dx.doi.org/10.3181/00379727-211-43950B

Genetics and Molecular Research 15 (3): gmr.15038541 
McDonald AA, Chang ES and Mykles DL (2011). Cloning of a nitric oxide synthase from green shore crab, Carcinus maenas: a comparative study of the effects of eyestalk ablation on expression in the molting glands (Y-organs) of $C$. maenas, and blackback land crab, Gecarcinus lateralis. Comp. Biochem. Physiol. A Mol. Integr. Physiol. 158: 150162. http://dx.doi.org/10.1016/j.cbpa.2010.10.013

Moncada S, Palmer RM and Higgs EA (1991). Nitric oxide: physiology, pathophysiology, and pharmacology. Pharmacol. Rev. 43: 109-142.

Qiao H, Fu H, Jin S, Wu Y, et al. (2012). Constructing and random sequencing analysis of normalized cDNA library of testis tissue from oriental river prawn (Macrobrachium nipponense). Comp. Biochem. Physiol. Part D Genomics Proteomics 7: 268-276. http://dx.doi.org/10.1016/j.cbd.2012.04.003

Radomski MW, Palmer RM and Moncada S (1991). Modulation of platelet aggregation by an L-arginine-nitric oxide pathway. Trends Pharmacol. Sci. 12: 87-88. http://dx.doi.org/10.1016/0165-6147(91)90510-Y

Rodríguez-Ramos T, Carpio Y, Bolívar J, Espinosa G, et al. (2010). An inducible nitric oxide synthase (NOS) is expressed in hemocytes of the spiny lobster Panulirus argus: cloning, characterization and expression analysis. Fish Shellfish Immunol. 29: 469-479. http://dx.doi.org/10.1016/j.fsi.2010.05.013

Rosselli M, Dubey RK, Imthurn B, Macas E, et al. (1995). Effects of nitric oxide on human spermatozoa: evidence that nitric oxide decreases sperm motility and induces sperm toxicity. Hum. Reprod. 10: 1786-1790.

Sudhamsu J and Crane BR (2009). Bacterial nitric oxide synthases: what are they good for? Trends Microbiol. 17: 212218. http://dx.doi.org/10.1016/j.tim.2009.02.003

Tamura K, Peterson D, Peterson N, Stecher G, et al. (2011). MEGA5: molecular evolutionary genetics analysis using maximum likelihood, evolutionary distance, and maximum parsimony methods. Mol. Biol. Evol. 28: 2731-2739. http://dx.doi.org/10.1093/molbev/msr121

Wang T, Ward M, Grabowski P and Secombes CJ (2001). Molecular cloning, gene organization and expression of rainbow trout (Oncorhynchus mykiss) inducible nitric oxide synthase (iNOS) gene. Biochem. J. 358: 747-755. http://dx.doi. org/10.1042/bj3580747

Wu CH, Siva VS and Song YL (2013). An evolutionarily ancient NO synthase (NOS) in shrimp. Fish Shellfish Immunol. 35: 1483-1500. http://dx.doi.org/10.1016/j.fsi.2013.08.016

Yao CL, Ji PF, Wang ZY, Li FH, et al. (2010). Molecular cloning and expression of NOS in shrimp, Litopenaeus vannamei. Fish Shellfish Immunol. 28: 453-460. http://dx.doi.org/10.1016/j.fsi.2009.12.002

Zhang F, Chen L, Wu P, Zhao W, et al. (2010). cDNA cloning and expression of Ubc9 in the developing embryo and ovary of Oriental river prawn, Macrobrachium nipponense. Comp. Biochem. Physiol. B Biochem. Mol. Biol. 155: 288-293. http://dx.doi.org/10.1016/j.cbpb.2009.11.013

Zhang YP, Qiao H, Zhang WY, Sun SM, et al. (2013). Molecular cloning and expression analysis of two sex-lethal homolog genes during development in the oriental river prawn, Macrobrachium nipponense. Genet. Mol. Res. 12: 4698-4711. http://dx.doi.org/10.4238/2013.October.18.8 